Cahiers $d u$ MONDE RUSSE

\section{Cahiers du monde russe}

Russie - Empire russe - Union soviétique et États indépendants

$43 / 4 \mid 2002$

Intellectuels et intelligentsia

\title{
Paul T. Christensen, Russia's workers in transition
}

\section{Myriam Désert}

\section{OpenEdition \\ Journals}

Édition électronique

URL : https://journals.openedition.org/monderusse/4042

DOI : $10.4000 /$ monderusse. 4042

ISSN : $1777-5388$

Éditeur

Éditions de l'EHESS

Édition imprimée

Date de publication : 30 décembre 2002

Pagination : 756-757

ISBN : 2-7132-1796-2

ISSN : $1252-6576$

Référence électronique

Myriam Désert, « Paul T. Christensen, Russia's workers in transition », Cahiers du monde russe [En ligne], 43/4 | 2002, mis en ligne le 17 juin 2009, consulté le 04 septembre 2022. URL : http:// journals.openedition.org/monderusse/4042 ; DOI : https://doi.org/10.4000/monderusse.4042

Ce document a été généré automatiquement le 4 septembre 2022.

Tous droits réservés 


\title{
Paul T. Christensen, Russia's workers in transition
}

\author{
Myriam Désert
}

\section{RÉFÉRENCE}

Paul T. CHRISTENSEN, Russia's workers in transition. Labor, management and the state under Gorbachev and Yeltsin. Dekalb, Northern Illinois University press, 1999, $197 \mathrm{p}$.

1 Le titre de cet ouvrage est quelque peu trompeur. Il ne s'agit pas d'une plongée dans la problématique de l'identité ouvrière (en dépit de la description des quelques combats emblématiques des années 1990, Paul T.Christensen n'a pas pour objectif de faire entendre la «parole ouvrière »). Et il récuse l'analyse «transitologique». Le sous-titre en revanche illustre bien le propos, qui est de prendre le triangle ouvriers-managers d'entreprise-État comme observatoire des changements économiques et politiques au cours de la dizaine d'années qui s'ouvre en Russie avec la perestroïka. Ce faisant, l'auteur montre comment, sur le terrain concret de l'entreprise, les percées de la démocratisation et les changements d'économie politique se combinent et/ou se contrarient, comment le système ancien se défait, tandis que les nouvelles institutions échouent à se faire.

2 Soulignant le caractère contradictoire des changements qui marquent la période (chap. 1, intitulé «Théorisation de l'économie politique du post-soviétisme»), l'auteur pointe les faiblesses de la notion de transition comme mode de description des mutations à l'œuvre. Les protagonistes décrits (ouvriers et managers) ont vu en effet leurs position et rôle concret s'inverser: si les grèves ouvrières de 1989-1990 ont contribué à achever d'affaiblir le système et tracé le chemin des nouvelles institutions, une fois affirmé le passage au marché, ce sont les dirigeants des entreprises qui occupent l'avant-scène. L'auteur enracine ces revirements dans l'histoire, elle aussi ambiguë, (rappelée dans le chap. 2, « La dictature et le prolétariat ») d'une classe ouvrière à la fois encensée et malmenée, dominée mais dotée d'un important potentiel de résistance 
passive. Il esquisse également une interrogation sur la centralité de la question de la " propriété » dans la libéralisation économique et politique.

Les chapitres 3 et 4 exposent, à partir d'études de cas concrets, l'absence de cohérence des premiers changements institutionnels, en quête de remèdes à la panne de productivité économique et idéologique, et leurs avatars aux mains des différents acteurs. La démocratisation du monde du travail, l'auto-administration, avec la création des "Conseils des travailleurs", auront été investies comme ferments de pouvoir ouvrier par le collectif de la KAMAZ (Kamskij avtomobil'nyj zavod), mais neutralisées par l'administration dans d'autres entreprises (jouant habilement des tensions entre groupes informels et syndicats plus ou moins institutionnalisés). Même sort pour l'autre dispositif de démocratisation que fut l'élection des dirigeants d'entreprise. Ces diverses monographies illustrent bien, pour cette phase, l'impossibilité de la démocratie interne, en l'absence de "démocratie externe ", c'est-à-dire tant que les usines restent sous la tutelle des ministères et des apparatchiks du parti.

4 Après la description de l'échec de la démocratie octroyée vient le récit de ce que l'on pourrait qualifier de "démocratie exercée »: les grèves de 1989-1991. Ce chapitre reprend les analyses usuelles sur l'évolution des grèves, le glissement des revendications, la difficulté à réinventer le syndicalisme.

5 La description de l'époque El'cin ne bénéficie pas du même éclairage "parlant » que constituent les études de cas qui illustrent la période précédente. Cela tient non seulement au caractère plus diffus des changements, mais aussi à la quasi-absence d'études de terrain (les difficultés de financement ont alors durement frappé les recherches), qui oblitère les chances de faire un jour une histoire vivante de la vie des entreprises dans ces années de transformation. Si les discussions qui ont accompagné les privatisations (supposées être un acte de justice sociale dans le discours eltsinien, appelées à clarifier les relations au sein de l'entreprise pour d'autres, etc.) sont bien relatées, l'auteur n'est pas en mesure de raconter les débats concrets qui ont animé telle ou telle entreprise au moment du vote entre les diverses variantes de privatisation proposées.

6 L'apport de cet ouvrage à la problématique de la " gouvernance » est donc plus ou moins riche selon les chapitres. Le chapitre conclusif du moins est sans ambiguïté : l'auteur y déplore les dommages que le néo-libéralisme fait subir à la démocratisation et proclame le rôle primordial qui doit être imparti, dans ce processus, aux relations dans le monde du travail. 